\title{
Synthesis and Molecular Structure of $4^{\prime}, 9^{\prime}, 4^{\prime \prime}, 9^{\prime \prime}$-Tetra-tert-butyl-1' $, 6^{\prime}, 1^{\prime \prime}, 6^{\prime \prime}$-tetramethoxy-2,5- dioxa[3.3] metabiphenylophane
}

\author{
Tetsuji Moriguchi, Tatsuya Egami, and Akihiko Tsuge \\ Department of Applied Chemistry, Faculty of Engineering, Kyushu Institute of Technology, 1-1 Sensui-cho, Tobata-ku, \\ Kitakyushu 804-8550, Japan \\ Correspondence should be addressed to Tetsuji Moriguchi; moriguch@che.kyutech.ac.jp
}

Received 3 September 2014; Accepted 13 October 2014; Published 23 November 2014

Academic Editor: Takashi Mino

Copyright (C) 2014 Tetsuji Moriguchi et al. This is an open access article distributed under the Creative Commons Attribution License, which permits unrestricted use, distribution, and reproduction in any medium, provided the original work is properly cited.

\begin{abstract}
A large calixarene-like metacyclophane, $4^{\prime}, 9^{\prime}, 4^{\prime \prime}, 9^{\prime \prime}$-tetra-tert-butyl-1', $6^{\prime}, 1^{\prime \prime}, 6^{\prime \prime}$-tetramethoxy-2,5-dioxa[3.3]metabiphenylophane, was synthesized by an intermolecular condensation reaction of its corresponding bischloromethyl-biphenyl and bishydroxymethylbiphenyl precursors. After molecular characterization by ${ }^{1} \mathrm{H}$ NMR spectroscopy and mass spectrometry, the compound generated single crystals by recrystallization from a dichloromethane/hexane mixture, facilitating an exact conformational determination via $\mathrm{X}$-ray diffraction analysis. The crystal was found to belong to the monoclinic space group $P 2{ }_{1} / n$ with cell parameters $a=19.908(2) \AA$, $b=9.7193(11) \AA, c=23.350(3) \AA, \beta=109.594(1)^{\circ}$, and $D_{\text {calc }}=1.150 \mathrm{~g} / \mathrm{cm}^{3}$ at $90 \mathrm{~K}$. The compound adopted quite strained $1,2-$ alternate-like conformations because its biphenyl parts displayed large dihedral angles and rigidity. The crystal did not incorporate any solvent molecule but its molecular cavity and crystal space were effectively filled by the substituents.
\end{abstract}

\section{Introduction}

Calixarenes are cyclic compounds consisting of aromatic rings and methylene bridge chains. In search for novel supramolecular hosts, numerous efforts have been deployed to decorate the upper or lower rim of calixarenes with various functional groups [1-3]. However, the nature of their cyclic skeleton clearly plays a central role in their remarkable performance as host molecules.

Members of the metacyclophane family [4-8], calixarenes, are readily obtained by base-assisted condensation of tert-butylphenol and formaldehyde into methylene-based bridges exclusively. In addition, several calixarene analogues such as $\left[1^{\mathrm{n}}\right]$ metacyclophanes containing oxygen $[9,10]$ or nitrogen $[11,12]$ instead of methylene groups in their bridges have been prepared. Cyclic compounds such as calix[4] arenes and large metacyclophanes present various conformations derived from the orientations of the aromatic parts [13]. In addition, the crystal structures of several cyclophanes have been reported using an alternative synthetic pathway [14] and cesium ion template effect [15-19]. Although large metacyclophanes comprising ether bridges and biphenyl units have been synthesized and their host-guest properties were reported $[20,21]$, their structures in the crystals were not determined.

In this study, we report the synthesis of "oxametabiphenilophanes," a new class of metacyclophanes that incorporate oxygen atoms in bridges and two biphenyl parts thus giving rigidity to the molecules (Scheme 1). A precursor mixture of bischloromethyl-biphenyl and bishidroxymethyl-biphenyl reacted under alkaline conditions to cyclize into the metacyclophane as a calix[4]arene analogue, which was readily separated from larger cyclization products and a resinous polymer byproduct using simple column chromatography. A crystal structure analysis was performed to determine the exact structure of the molecule.

\section{Materials and Methods}

All reagents and solvents were obtained from commercial sources and used as received. The ${ }^{1} \mathrm{H}-\mathrm{NMR}$ spectrum was recorded by a JEOL JNM A-500 spectrometer in $\mathrm{CDCl}_{3}$ with tetramethylsilane as an internal reference. The electron 


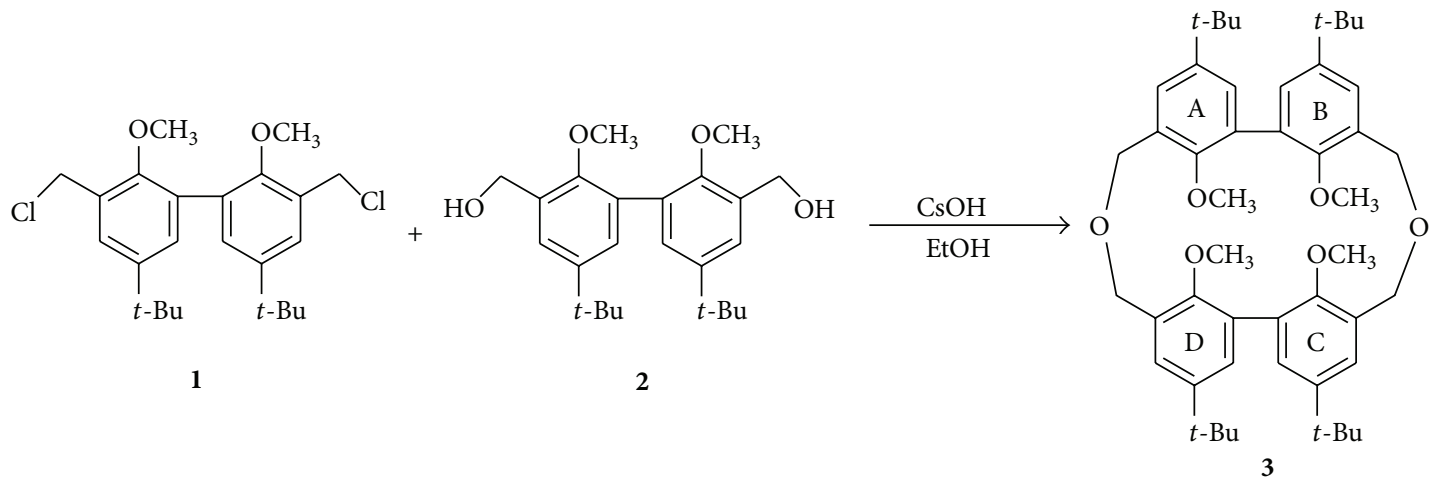

Scheme 1: $4^{\prime}, 9^{\prime}, 4^{\prime \prime}, 9^{\prime \prime}$-Tetra-tert-butyl-1' $, 6^{\prime}, 1^{\prime \prime}, 6^{\prime \prime}$-tetramethoxy-2,5-dioxa[3.3]metabiphenylophane 3 (right) and its precursors $\mathbf{1}, \mathbf{2}$ (left).

impact mass spectrum (EI-MS) of the compound was obtained in dichloromethane as the solvent using a JEOL JMS-SX102A spectrometer. The instrument was operated in the positive ion mode over an $\mathrm{m} / \mathrm{z}$ range of $100-1200$. The elemental analysis was performed using a YANAKO MT-5 $\mathrm{CHN}$ analyzer.

\subsection{Synthesis of $4^{\prime}, 9^{\prime}, 4^{\prime \prime}, 9^{\prime \prime}$-Tetra-tert-butyl-1 $1^{\prime}, 6^{\prime}, 1^{\prime \prime}, 6^{\prime \prime}$ -} tetramethoxy-2,5-dioxa[3.3] metabiphenylophane 3 (Scheme 1). $3,3^{\prime}$-Bischloromethyl-2,2' -dimethoxy-5, $5^{\prime}$-di-tert-butylbiphenyl $1(0.423 \mathrm{~g}, 1.00 \mathrm{mmol})$ and $3,3^{\prime}$-bishydroxymethyl$2,2^{\prime}$-dimethoxy-5, $5^{\prime}$-di-tert-butylbiphenyl 2 (0.386 g, 1.00 $\mathrm{mmol}$ ) were dissolved in a 1:1 benzene/ethanol mixture $(150 \mathrm{~mL})$ and the resulting solution was added dropwise to reflux ethanol $(300 \mathrm{~mL})$ containing the alkaline catalyst $\mathrm{Cs}_{2} \mathrm{CO}_{3}(1.96 \mathrm{~g}, 6.00 \mathrm{mmol})$ by using a high-dilution principle technique [12-15]. The reaction mixture was stirred at reflux temperature for $3 \mathrm{~h}$ before solvent removal by rotary evaporation. A solution of $1 \%$ aqueous $\mathrm{HCl}$ was added to the resulting residue, and the mixture was extracted with dichloromethane $(100 \mathrm{~mL} \times 3)$. The combined organic layers were washed with brine, dried over $\mathrm{MgSO}_{4}$, filtered, and evaporated to dryness under vacuum. The resulting residue was purified by silica gel chromatography (Wako C-300) using 1:1 dichloromethane/hexane as an eluent to give the desired compound $4^{\prime}, 9^{\prime}, 4^{\prime \prime}, 9^{\prime \prime}$-tetra-tert-butyl-1 $1^{\prime}, 6^{\prime}, 1^{\prime \prime}, 6^{\prime \prime}$ tetramethoxy-2,5-dioxa[3.3] metabiphenylophane 3 (260 mg, $36 \%)$ as a white solid.

Single crystals were obtained by vapor diffusion of a dichloromethane/hexane solution of the metabiphenylophane at room temperature.

M.p. $286^{\circ} \mathrm{C}-288^{\circ} \mathrm{C} .{ }^{1} \mathrm{H}$ NMR $\left(500 \mathrm{MHz}, \mathrm{CDCl}_{3}\right) 1.33$ (s, $36 \mathrm{H}$, tert-butyl H), 2.90 (s, $12 \mathrm{H}$, methoxy C-H), 4.28 (d, $4 \mathrm{H}$, ether bridge $\mathrm{C}-\mathrm{H}, J=11.5 \mathrm{~Hz}), 4.76(\mathrm{~d}, 4 \mathrm{H}$, ether bridge $\mathrm{C}-$ $\mathrm{H}, J=11.5 \mathrm{~Hz}), 7.27(\mathrm{~d}, 4 \mathrm{H}$, biphenyl C-H, $J=3.0 \mathrm{~Hz})$, and 7.36 (d, $4 \mathrm{H}$, biphenyl C-H, $J=3.0 \mathrm{~Hz})$. EI-MS $(50 \mathrm{eV}): \mathrm{m} / z$ $736\left(\mathrm{M}^{+}\right)$. Elemental analysis: C $77.98 \%(78.22 \%$, calcd. $)$ and H $8.70 \%$ (8.75\%, calcd.).

2.2. Single Crystal X-Ray Analysis and Structure Determination (Table 1). A colorless prismatic crystal of $4^{\prime}, 9^{\prime}, 4^{\prime \prime}, 9^{\prime \prime}$-tetra-tert-butyl-1', $6^{\prime}, 1^{\prime \prime}, 6^{\prime \prime}$-tetramethoxy-2,5dioxa[3.3] metabiphenylophane 3 measuring approximately $0.40 \mathrm{~mm} \times 0.35 \mathrm{~mm} \times 0.25 \mathrm{~mm}$ was mounted on a glass fiber. The data was collected on a Bruker APEX II KY CCD diffractometer by using a graphite-monochromatized $\mathrm{Mo} / \mathrm{K} \alpha$ radiation $(\lambda=0.71073 \AA$ ) and a nominal crystal-to-area detector distance of ca. $83 \mathrm{~mm}$.

These measurements were performed at $90 \mathrm{~K}$ to a maximum $2 \theta$ value of $28.65^{\circ}(0.74 \AA$ resolution $)$. The preliminary unit cell determination was conducted using the APEX2 software [22], and the integrated intensity determination and unit cell refinement were performed using the SAINT program [23]. Of the 48529 collected reflections, 10321 were unique $\left(R_{\text {int }}=0.0234, R_{\sigma}=0.0180\right)$ and equivalent reflections were merged. The linear absorption coefficient, $\mu$, for $\mathrm{Mo} / \mathrm{K} \alpha$ radiation equaled $0.074 \mathrm{~cm}^{-1}$.

An empirical absorption correction provided transmission factors ranging from 0.880 to 0.980 [24]. Data were corrected for Lorentz and polarization effects.

The structure was solved by the SHELXS-97 direct method [25], and subsequent structure refinements were performed using SHELXL-97 [26]. All nonhydrogen atoms were refined using anisotropic displacement parameters. Hydrogen atoms at carbon atoms were added geometrically and refined using a riding model (constrained).

The final cycle for the full-matrix least-squares refinement on $F^{2}$ was based on 10321 observed reflections and 503 variable parameters and converged with unweighted and weighted agreement factors of $R_{1}=\Sigma|| F_{O}|-| F_{c}|| / \Sigma\left|F_{O}\right|=$ 0.0306 and $w R_{2}=\left[\Sigma\left(w\left(F_{o}{ }^{2}-F_{c}{ }^{2}\right)^{2}\right) / \Sigma w\left(F_{o}{ }^{2}\right)^{2}\right]^{1 / 2}=0.0843$, respectively. The standard deviation amounted to 1.072 for the unit weight observations (Sstandard deviation of an observation of unit weight: $\left[\Sigma w\left(F_{o}{ }^{2}-F_{c}{ }^{2}\right)^{2} /\left(N_{o}-N_{v}\right)\right]^{1 / 2}$, where $N_{o}=$ number of observations and $N_{v}=$ number of variables) and sigma weights were used in the LS calculation (least Squares function minimized: (SHELXL-97): $\Sigma w\left(F_{o}{ }^{2}-\right.$ $\left.F_{c}^{2}\right)^{2}$, where $w=$ Least Squares weights).

The CIF data only showed one "Alert B" in the online check report of the Cambridge Crystal Data Centre (CCDC). This alert is related to the completeness of theta, which equaled $94.4 \%$ due to the crystal shape. Alerts A and C were not observed. 
TABLE 1: Crystallographic data for $4^{\prime}, 9^{\prime}, 4^{\prime \prime}, 9^{\prime \prime}$-tetra-tert-butyl$1^{\prime}, 6^{\prime}, 1^{\prime \prime}, 6^{\prime \prime}$-tetramethoxy-2,5-dioxa[3.3] metabiphenylophane 3.

\begin{tabular}{|c|c|c|}
\hline Empirical f & $\mathrm{C}_{48} \mathrm{H}_{64} \mathrm{O}_{6}$ & \\
\hline Formula weight & 736.99 & \\
\hline Temperature & $90 \mathrm{~K}$ & \\
\hline Wavelength & $0.71073 \AA$ & \\
\hline Crystal system & Monoclinic & \\
\hline \multirow[t]{2}{*}{ Space group } & $P 2_{1} / n($ no. 14$)$ & \\
\hline & $a=19.908(2) \AA$ & \\
\hline \multirow[t]{2}{*}{ Unit cell dimensions } & $b=9.7193(11) \AA$ & $\begin{array}{c}\beta= \\
109.594(1)^{\circ}\end{array}$ \\
\hline & $c=23.350(3) \AA$ & \\
\hline Volume & $4256.5(8) \AA^{-3}$ & \\
\hline$Z$ & 4 & \\
\hline Density (calculated) & $1.150 \mathrm{~g} / \mathrm{cm}^{3}$ & \\
\hline Absorption coefficient & $0.074 \mathrm{~mm}^{-1}$ & \\
\hline$F(000)$ & 1600 & \\
\hline Crystal size & $0.400 \times 0.350 \times 0.250 \mathrm{~mm}$ & \\
\hline $\begin{array}{l}\text { Theta range for data } \\
\text { collection }\end{array}$ & $1.17^{\circ}$ to $28.65^{\circ}$ & \\
\hline Index ranges & $\begin{array}{c}-26 \leq h \leq 26,-13 \leq k \leq \\
13,-29 \leq l \leq 30\end{array}$ & \\
\hline Reflections collected & 48529 & \\
\hline Independent reflections & $10321[R(\mathrm{int})=0.0234]$ & \\
\hline Reflections $[I>2 \operatorname{sigma}(I)]$ & 9126 & \\
\hline $\begin{array}{l}\text { Completeness to theta }= \\
28.65^{\circ}\end{array}$ & $94.4 \%$ & \\
\hline Absorption correction & Empirical & \\
\hline Refinement method & $\begin{array}{l}\text { Full-matrix least-squares } \\
\text { on } F^{2}\end{array}$ & \\
\hline Data/restraints/parameters & $10321 / 0 / 503$ & \\
\hline Goodness-of-fit on $F^{2}$ & 1.072 & \\
\hline $\begin{array}{l}\text { Final } R_{1} \text { indices }[I> \\
2 \operatorname{sigma}(I)]\end{array}$ & $R_{1}=0.0408, w R_{2}=0.1157$ & \\
\hline$w R_{2}$ indices (all data) & $R_{1}=0.0476, w R_{2}=0.1279$ & \\
\hline $\begin{array}{l}\text { Largest diff. peak and hole } \\
\text { (RMS deviation of } \\
0.11 \mathrm{e} / \AA^{3} \text { ) }\end{array}$ & 0.476 and $-0.331 \mathrm{e}^{-3}$ & \\
\hline
\end{tabular}

Crystal details such as the atomic coordinates, displacement parameters, bond lengths, and bond angles appear in the Additional Information Section.

\section{Results and Discussion}

3.1. Synthesis of $4^{\prime}, 9^{\prime}, 4^{\prime \prime}, 9^{\prime \prime}$-Tetra-tert-butyl-1', $6^{\prime}, 1^{\prime \prime}, 6^{\prime \prime}$-tetramethoxy-2,5-dioxa[3.3]metabiphenylophane 3 (Scheme 1). The dioxa[3.3] metacyclophane was synthesized from the precursors biphenyl derivatives $3,3^{\prime}$-bischloromethyl-2,2 ${ }^{\prime}$ dimethoxy-5,5' -di-tert-butylbiphenyl 1 and 3,3'-bishydroxymethyl-2,2' -dimethoxy-5, $5^{\prime}$-di-tert-butylbiphenyl 2 by using cesium ion template effect and high-dilution principle techniques. Cyclization conditions were quite general for the
TABLE 2: Selected bond lengths $(\AA)$ and angles $\left(^{\circ}\right)$ in $4^{\prime}, 9^{\prime}, 4^{\prime \prime}, 9^{\prime \prime}$ tetra-tert-butyl-1' $6^{\prime}, 1^{\prime \prime}, 6^{\prime \prime}$-tetramethoxy-2,5-dioxa[3.3]metabiphenylophane 3 .

\begin{tabular}{llll}
\hline O1-C9 & $1.4308(13)$ & O4-C31 & $1.4355(13)$ \\
O1-C10 & $1.4340(13)$ & O4-C32 & $1.4345(13)$ \\
O2-C7 & $1.3878(12)$ & O5-C34 & $1.3807(12)$ \\
O2-C17 & $1.4365(14)$ & O5-C35 & $1.4329(13)$ \\
O3-C29 & $1.3804(12)$ & O6-C38 & $1.3839(12)$ \\
O3-C30 & $1.4421(13)$ & O6-C39 & $1.4275(15)$ \\
\hline C9-O1-C10 & $114.17(8)$ & C31-O4-C32 & $112.97(8)$ \\
O1-C9-C8 & $114.15(8)$ & O4-C31-C28 & $111.80(8)$ \\
O1-C10-C12 & $114.25(9)$ & O4-C32-C33 & $108.01(8)$ \\
C7-O2-C17 & $114.30(8)$ & C35-O5-C34 & $114.57(8)$ \\
C30-O3-C29 & $116.28(8)$ & C39-O6-C38 & $113.29(9)$ \\
\hline
\end{tabular}

synthesis of macrocyclic compounds. The desired compound 3 was readily isolated as a colorless solid by simple silica gel column chromatography in moderate yield (36\%). The remaining residue contained larger macrocyclic compounds and resinous materials.

3.2. Characterization of $4^{\prime}, 9^{\prime}, 4^{\prime \prime}, 9^{\prime \prime}$-Tetra-tert-butyl-1', $6^{\prime}, 1^{\prime \prime}$, $66^{\prime \prime}$-tetramethoxy-2,5-dioxa[3.3]metabiphenylophane 3 . The EI mass spectrum of the compound $\mathbf{3}$ at an ionization voltage of $50 \mathrm{eV}$ exhibited only one intensive signal with characteristic isotopic patterns for $[\mathrm{M}]^{+}$. Its ${ }^{1} \mathrm{H}$ NMR spectrum only showed two doublets corresponding to the aromatic protons of the biphenyl groups in addition to the signals of the four tert-butyl and the four methoxy groups. Bridge ether protons also appeared as two doublets, making the exact structure of the molecule easy to determine via simple ${ }^{1} \mathrm{H}$ NMR analysis. When measurement temperature is raised, the bridge ether protons also changed to two singlets.

The molecular structure seems to be rigid in deuterated chloroform at $297 \mathrm{~K}$, but the structure is readily moved by raising the measurement temperature.

To the best of our knowledge, this is the first time that the exact structure and crystal packing of this cyclophane have been characterized using X-ray analysis.

Compound 3 crystallizes as its 1,2-alternate-type conformers in the centrosymmetric space group $P 2_{1} / n$ (number $14 ; Z=4$; Figure 1). Table 2 lists the selected bond lengths $(\AA)$ and bond angles $\left({ }^{\circ}\right)$ for the compound. Notably, the two ether bridges of the [3.3] metacyclophane ring adopt a pseudo-boat conformation [27-29].

In general, cyclic compounds, such as calixarenes and large-sized metacyclophanes, display many conformations in solution. For example, tetrahydroxycalix [4] arene exhibits four typical conformations, including cone, partial cone, 1,2alternate, and 1,3-alternate (Figure 1) [30]. In this study, the dioxa[3.3]metacyclophane presents a pseudo-1,2-alternate conformation. Moreover, its structure appears more rigid than calix[4]arenes because of its two rigid substituted biphenyl components. Furthermore, no solvent molecules are included in the crystals (Figure 2). 

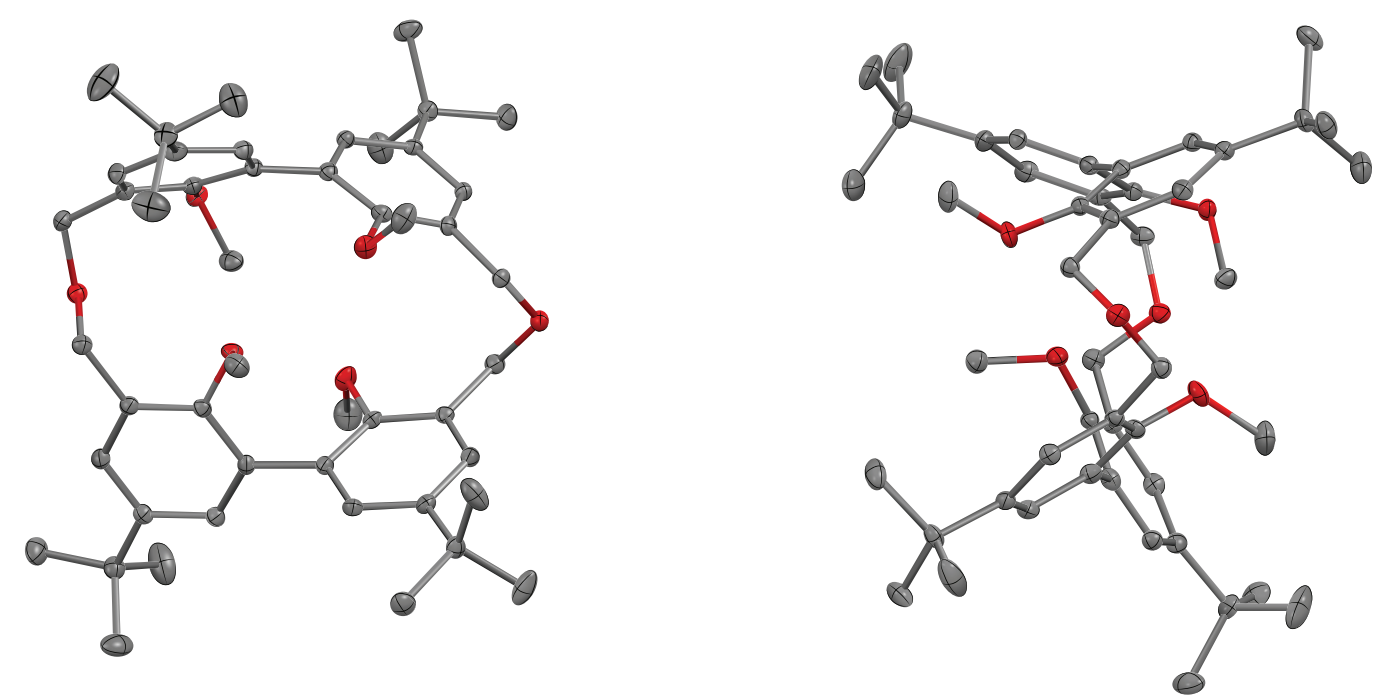

(a)

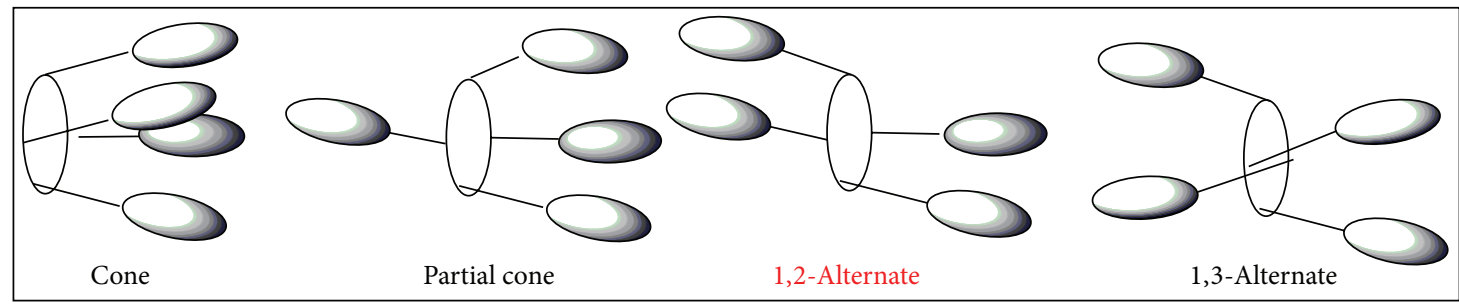

(b)

Figure 1: (a) Top and (b) side views of $4^{\prime}, 9^{\prime}, 4^{\prime \prime}, 9^{\prime \prime}$-tetra-tert-butyl-1 $1^{\prime}, 6^{\prime}, 1^{\prime \prime}, 6^{\prime \prime}$-tetramethoxy-2,5-dioxa[3.3]metabiphenylophane 3. Only one of the two 1,2-alternate isomers is shown. Displacement ellipsoids are drawn at the $50 \%$ probability level. All hydrogen atoms are omitted for clarity. The red and grey ellipsoids represent $\mathrm{O}$ and $\mathrm{C}$ atoms, respectively.

Some intermolecular short contacts existed in the crystal, which are shown in Figure 3 and are listed in Table 3. Hydrophobic tert-butyl groups form two-dimensional hydrophobic domains along the (004) crystallographic planes of Miller indexes with a $d 002$ repetition pattern. Interestingly, one of the methoxy groups (highlighted by a red square in Figure 4) is located in the cyclophane cavity and the tert-butyl groups effectively fill the crystal. These structural features limit the presence of other cyclophane conformers in the crystal.

The structure of dioxa[3.3] metabiphenilophane 3 is quite strained in the crystal lattice, which can be attributed to the angular differences between the phenyl rings ( $\mathrm{Cl}-$ C2-C3-C4-C5-C6: ring A, C7-C8-C9-C10-C11-C12: ring $\mathrm{B}, \mathrm{C13}-\mathrm{C} 14-\mathrm{C} 15-\mathrm{C} 16-\mathrm{C} 17-\mathrm{C} 18$ : ring $\mathrm{C}$, and C19-C20-C21C22-C23-C24: ring D, resp.). In the biphenyl ring planes, the dihedral angles amount to $81.62^{\circ}$ between rings $\mathrm{A}$ and $\mathrm{B}$ and $53.73^{\circ}$ between rings $\mathrm{C}$ and $\mathrm{D}$ rings. This discrepancy may be explained by the presence of the ether bridges linking the biphenyl parts and that of several bulky substituents at neighboring positions. Furthermore, it may stem from the cyclophane ring structure and molecular packing in the crystal. In general, phenyl rings can rotate variably in biphenyls and the angle between these
TABLE 3: Short contacts ( $\AA$ ) between neighboring $4^{\prime}, 9^{\prime}, 4^{\prime \prime}, 9^{\prime \prime}$-tetratert-butyl-1' $6^{\prime}, 1^{\prime \prime}, 6^{\prime \prime}$-tetramethoxy-2,5-dioxa[3.3]metabiphenylophane molecules in the crystal.

\begin{tabular}{lccc}
\hline C9-C9* $^{*}$ & $3.337(9)$ & H45A-H44A** & 2.384 \\
C9-H9A $^{*}$ & 2.814 & H44A-H45A & 2.384 \\
H9A-C9* $^{* * *}$ & 2.814 & & \\
\hline
\end{tabular}

phenyl rings depends on the steric hindrance from the substituents.

\section{Conclusions}

The large metacyclophane $4^{\prime}, 9^{\prime}, 4^{\prime \prime}, 9^{\prime \prime}$-tetra-tert-butyl$1^{\prime}, 6^{\prime}, 1^{\prime \prime}, 6^{\prime \prime}$-tetramethoxy-2,5-dioxa[3.3] metabiphenylophane 3 consisting of two biphenyl components linked through two ether bridges was synthesized and characterized by ${ }^{1} \mathrm{H}$ NMR, EI-MS, and elemental analysis. Its exact structure in the solid state was also determined by single crystal X-ray diffraction. Only two enantiomers were present in the centrosymmetric unit cell and no solvent molecules were detected. The crystal space and the molecular cavity were filled effectively by the tert-butyl and methoxy substituents. 

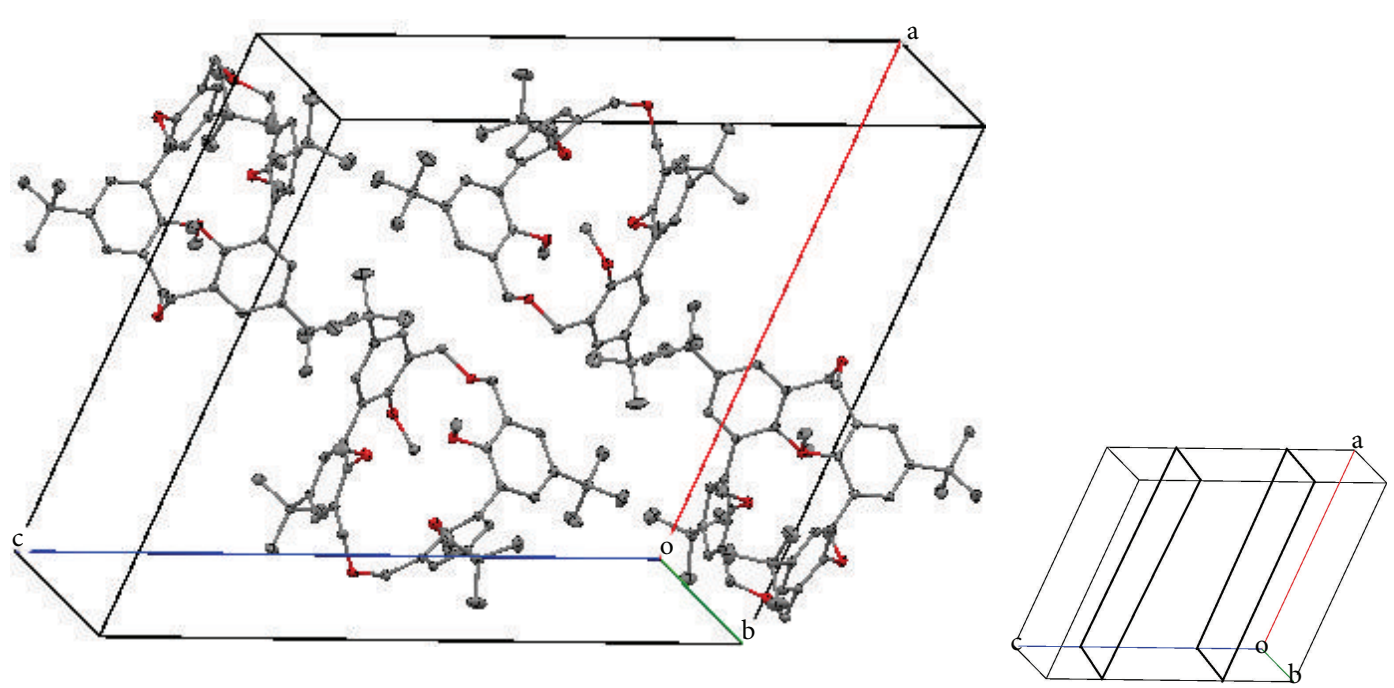

FiguRE 2: Crystal packing of $4^{\prime}, 9^{\prime}, 4^{\prime \prime}, 9^{\prime \prime}$-tetra-tert-butyl-1', $6^{\prime}, 1^{\prime \prime}, 6^{\prime \prime}$-tetramethoxy-2,5-dioxa[3.3]metabiphenylophane 3. Red and grey ellipsoids represent $\mathrm{O}$ and $\mathrm{C}$ atoms, respectively. All hydrogen atoms are omitted for clarity.

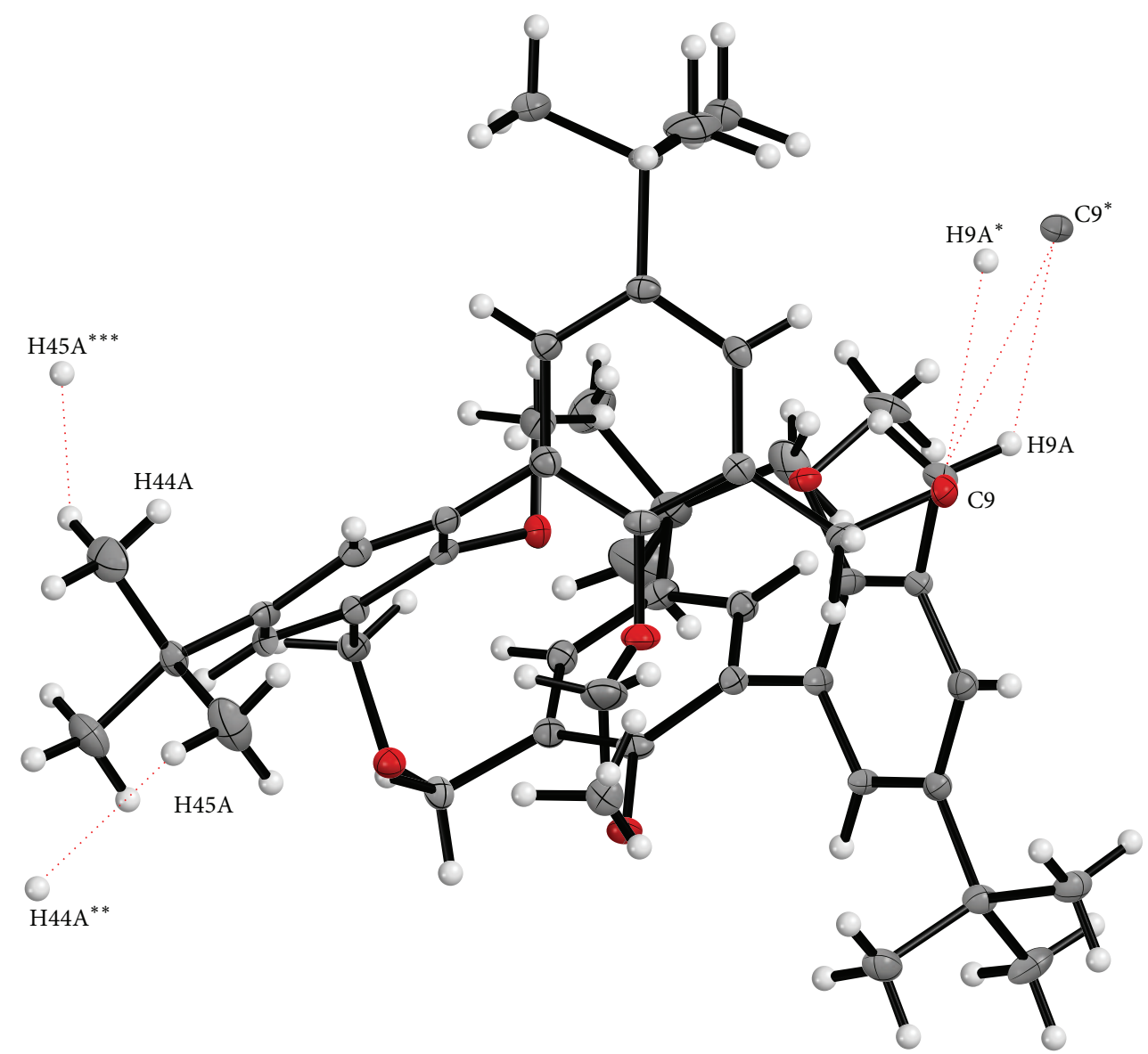

FIGURE 3: Short contacts between neighboring $4^{\prime}, 9^{\prime}, 4^{\prime \prime}, 9^{\prime \prime}$-tetra-tert-butyl-1', $6^{\prime}, 1^{\prime \prime}, 6^{\prime \prime}$-tetramethoxy-2,5-dioxa[3.3]metabiphenylophane molecules. The red and grey ellipsoids represent $\mathrm{O}$ and $\mathrm{C}$ atoms, respectively. 


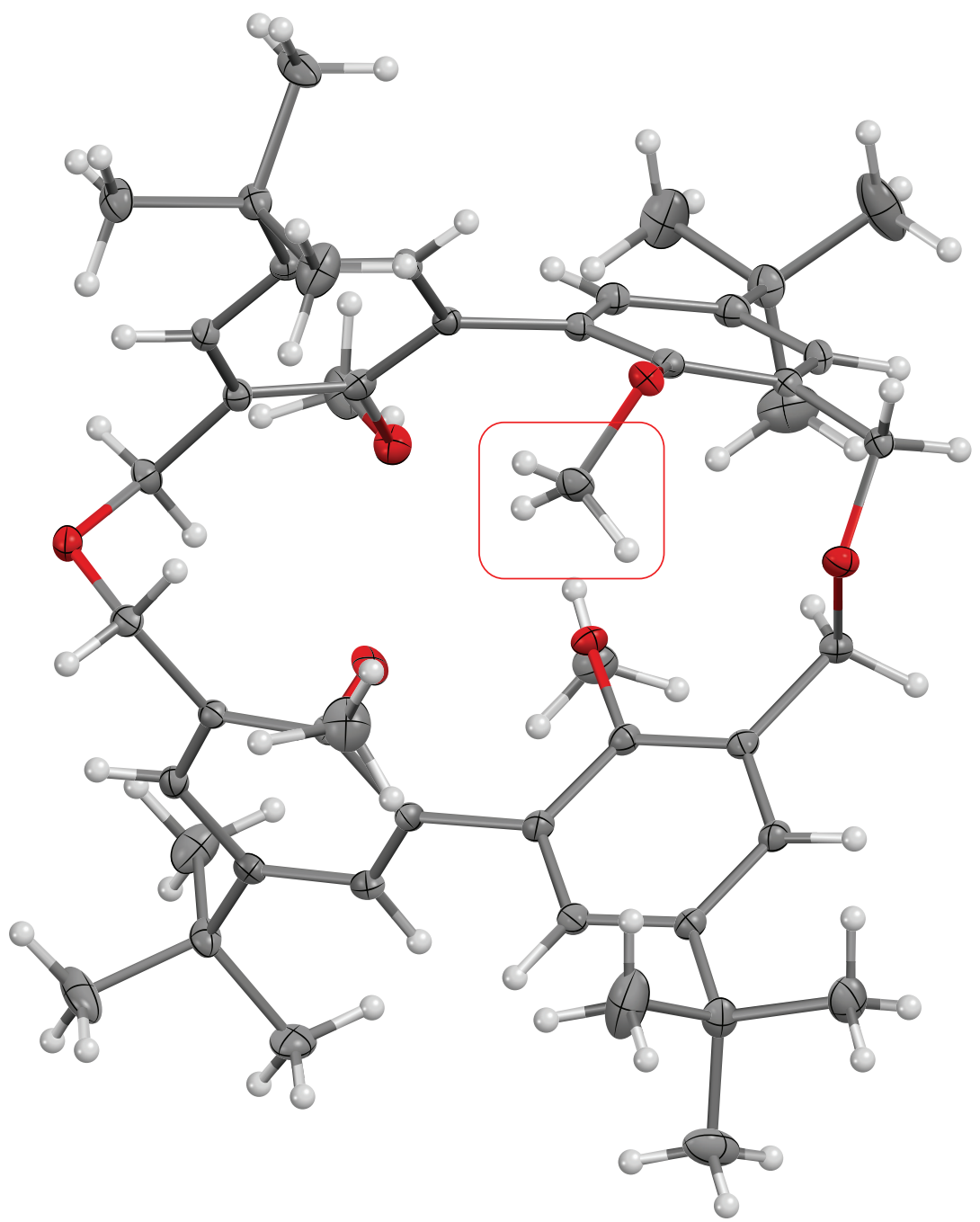

FIgURE 4: Intramolecular cavity is filled with the methoxy substituent of $4^{\prime}, 9^{\prime}, 4^{\prime \prime}, 9^{\prime \prime}$-tetra-tert-butyl-1' $, 6^{\prime}, 1^{\prime \prime}, 6^{\prime \prime}$-tetramethoxy-2,5dioxa[3.3] metabiphenylophane 3. The red and grey ellipsoids represent $\mathrm{O}$ and $\mathrm{C}$ atoms, respectively. The red square highlights the methoxy group in the cyclophane cavity.

\section{Additional Information}

CCDC no. 1012517 contains the supplementary crystallographic data for the compound $(2 S, 5 S)$ tert-butyl 3-oxo-2oxa-5-azabicyclo[2.2.2] octane-5-carboxylate. The data can be obtained free of charge via http://www.ccdc.cam.ac.uk/data request/cif by e-mailing data_request@ccdc.cam.ac.uk, or by contacting The Cambridge Crystallography Data Centre, 12 Union Road, Cambridge, CB2 IEZ, UK.

\section{Conflict of Interests}

The authors declare that there is no conflict of interests regarding the publication of this paper.

\section{Acknowledgments}

The authors are grateful for the Center for Instrumental Analysis, Kyushu Institute of Technology (KITCIA), for the EI_MS, ${ }^{1} \mathrm{H}$ NMR, and X-ray analyses. The authors also thank Dr. Kenji Yoza (Bruker AXS JAPAN) for experimental assistance during the final stages of the $\mathrm{X}$-ray analysis.

\section{References}

[1] C. D. Gutsche, Calixarenes, Royal Society of Chemistry, Cambridge, UK, 1989.

[2] "Calixarenes," in Compendium of Chemical Terminology: The Gold Book, IUPAC, Ed., Compiled by A. D. McNaught, A. Wilkinson, Blackwell Scientific, Oxford, UK, 2nd edition, 1997.

[3] G. McMahon, S. O’Malley, K. Nolan, and D. Diamond, "Important calixarene derivatives-their synthesis and applications," Arkivoc, vol. 2003, no. 7, pp. 23-31, 2003.

[4] F. Diederich, P. J. Stang, and R. R. Tykwinski, Modern Supramolecular Chemistry: Strategies for Macrocycle Synthesis, John Wiley \& Sons, New York, NY, USA, 2008.

[5] V. Boekelheide, "Syntheses and properties of the $\left[2_{n}\right]$ Cyclophanes," in Cyclophanes I, vol. 113 of Topics in Current Chemistry, pp. 87-143, Springer, Berlin, Germany, 1983. 
[6] P. M. Keehn and S. M. Rosenfeld, Eds., Cyclophanes, vol. I, II, Academic Press, New York, NY, USA, 1983.

[7] F. Diederich, Cyclophanes, Royal Society of Chemistry, Cambridge, UK, 1991.

[8] F. Vogtle, Cyclophane Chemistry, John Wiley \& Sons, New York, NY, USA, 1993.

[9] G. J. Bodwell, "The new inductees in the "hall of phane"-no phane, no gain," Angewandte Chemie International Edition in English, vol. 35, pp. 2085-2088, 1996.

[10] A. de Meijere and B. König, "What is new in [2.2]paracyclophane chemistry?” Synlett, vol. 1997, no. 11, pp. 1221-1232, 1997.

[11] M. P. Weaver and C. Y. Meyers, "Cyclic ethers from the self-condensation of 4, 6-dimethylol-m-xylene," Tetrahedron Letters, vol. 1, no. 18, pp. 7-10, 1959.

[12] B. Dhawan and C. D. Guche, "Calixarenes. 10. Oxacalixarenes," The Journal of Organic Chemistry, vol. 48, pp. 1536-1539, 1983.

[13] I. U. Khan, H. Takemura, M. Suenaga, T. Shinmyozu, and T. Inazu, "Metacyclophanes and related compounds. 26. Tetrahydroxy[2.n.2.n]metacyclophanes. Preparation, reactions, and spectra," The Journal of Organic Chemistry, vol. 55, pp. 24042409, 1990.

[14] L. Rossa and F. Vögtle, "Synthesis of medio- and macrocyclic compounds by high dilution principle techniques," in Cyclophanes I, Topics in Current Chemistry, pp. 1-86, 1983.

[15] P. Navarro, M. I. Rodríguez-Franco, C. Foces-Foces, F. Cano, and A. Samat, "Selective carriers of ammonium ions. I. Synthesis and template effect of cesium chloride and x-ray structure and ionophoric properties of polyether crowns containing 1-methyl-3,5-bis(methylene)-1H-pyrazole units," Journal of Organic Chemistry, vol. 54, no. 6, pp. 1391-1398, 1989.

[16] F. Vogtle and E. Weber, Host Guest Complex Chemistry, vol. 1 of Topics in Current Chemistry, 1981.

[17] F. Vogtle and E. Weber, Host Guest Complex Chemistry, vol. 2 of Topics in Current Chemistry, 1982.

[18] F. Vogtle and E. Weber, Host Guest Complex Chemistry, vol. 3 of Topics in Current Chemistry, 1984.

[19] M. Kamali, A. Shockravi, R. Mohtasham, and S. P. Moghanlo, "Synthesis of new aza- and thia-crown ethers and their metal ion templates synthesis as model case study," Arkivoc, vol. 2014, no. 4, pp. 242-251, 2014.

[20] K. E. Koenig, G. M. Lein, P. Stuckler, T. Kaneda, and D. J. Cram, "Host-guest complexation. 16. Synthesis and cation binding characteristics of macrocyclic polyethers containing convergent methoxyaryl groups," Journal of the American Chemical Society, vol. 101, no. 13, pp. 3553-3566, 1979.

[21] R. C. Helgeson, T. L. Tarnowski, and D. J. Cram, "Hostguest complexation. 19. Cyclic, bicyclic, and tricyclic polyether systems," Journal of Organic Chemistry, vol. 44, no. 14, pp. 25382550, 1979.

[22] APEX2 Version 2009.9, Bruker AXS, 2009.

[23] SAINT Version 7.68A, Bruker AXS, 2009.

[24] G. M. Sheldrick, SADABS Version 2008/1, Bruker AXS, 2008.

[25] G. M. Sheldrick, "A short history of SHELX," Acta Crystallographica Section A: Foundations of Crystallography, vol. 64, no. 1, pp. 112-122, 2007.

[26] G. M. Sheldrick, "A short history of SHELX," Acta Crystallographica Section A: Foundations of Crystallography, vol. 64, part 1, pp. 112-122, 2008.

[27] L. K. Doamekpor, V. K. Nartey, R. K. Klake, and T. Yamato, "Synthesis and conformational studies of some metacyclophane compounds," International Journal of Organic Chemistry, vol. 2, pp. 152-158, 2012.

[28] A. Tsuge, N. Takagi, T. Kakara, T. Moriguchi, and K. Sakata, "Preparation, conformation and reaction of medium-sized [1.n.n]metacyclophanes," Chemistry Letters, vol. 29, no. 8, pp. 948-949, 2000.

[29] Y. Fukazawa, Y. Takeda, S. Usui, and M. Kodama, "Synthesis and conformation of 1,1,10,10-tetramethyl[3.3]metacyclophane," Journal of the American Chemical Society, vol. 110, no. 23, pp. 7842-7847, 1988.

[30] S. Simaan and S. E. Biali, "A "classical" tetrahydroxycalix[4] arene adopting the 1,2-alternate conformation," Journal of Organic Chemistry, vol. 69, no. 1, pp. 95-98, 2004. 

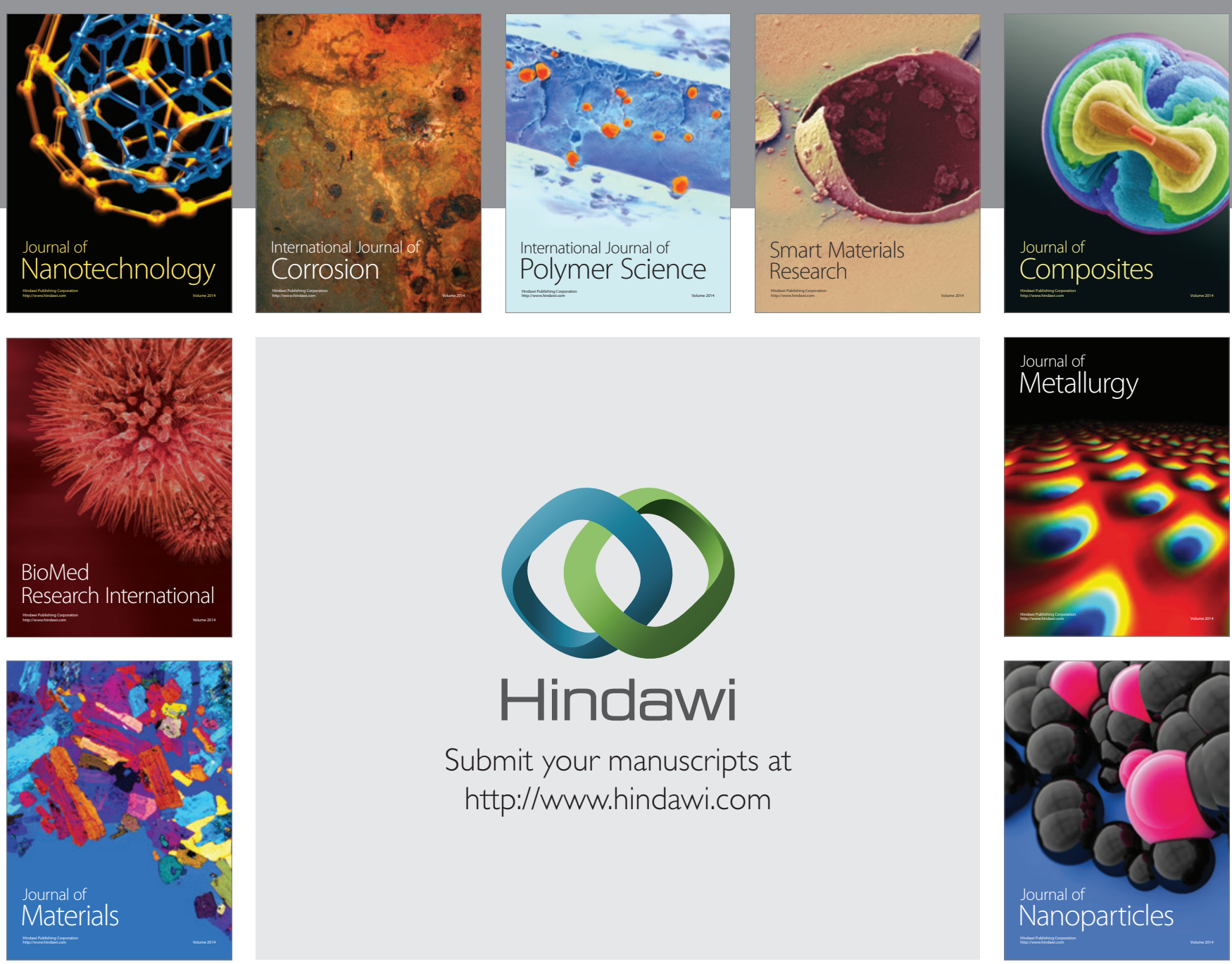

Submit your manuscripts at http://www.hindawi.com
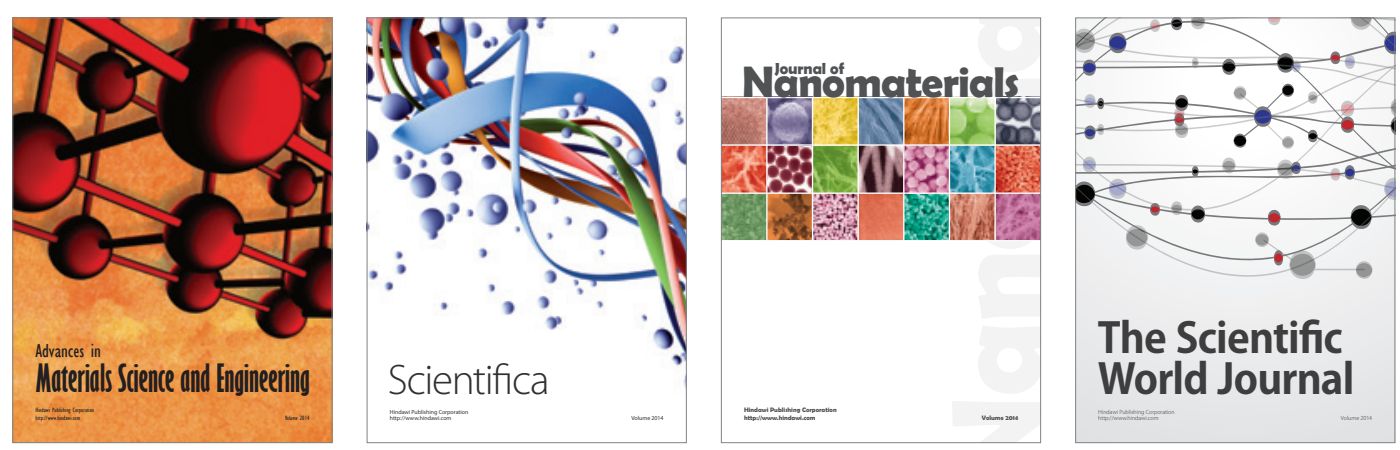

\section{The Scientific World Journal}
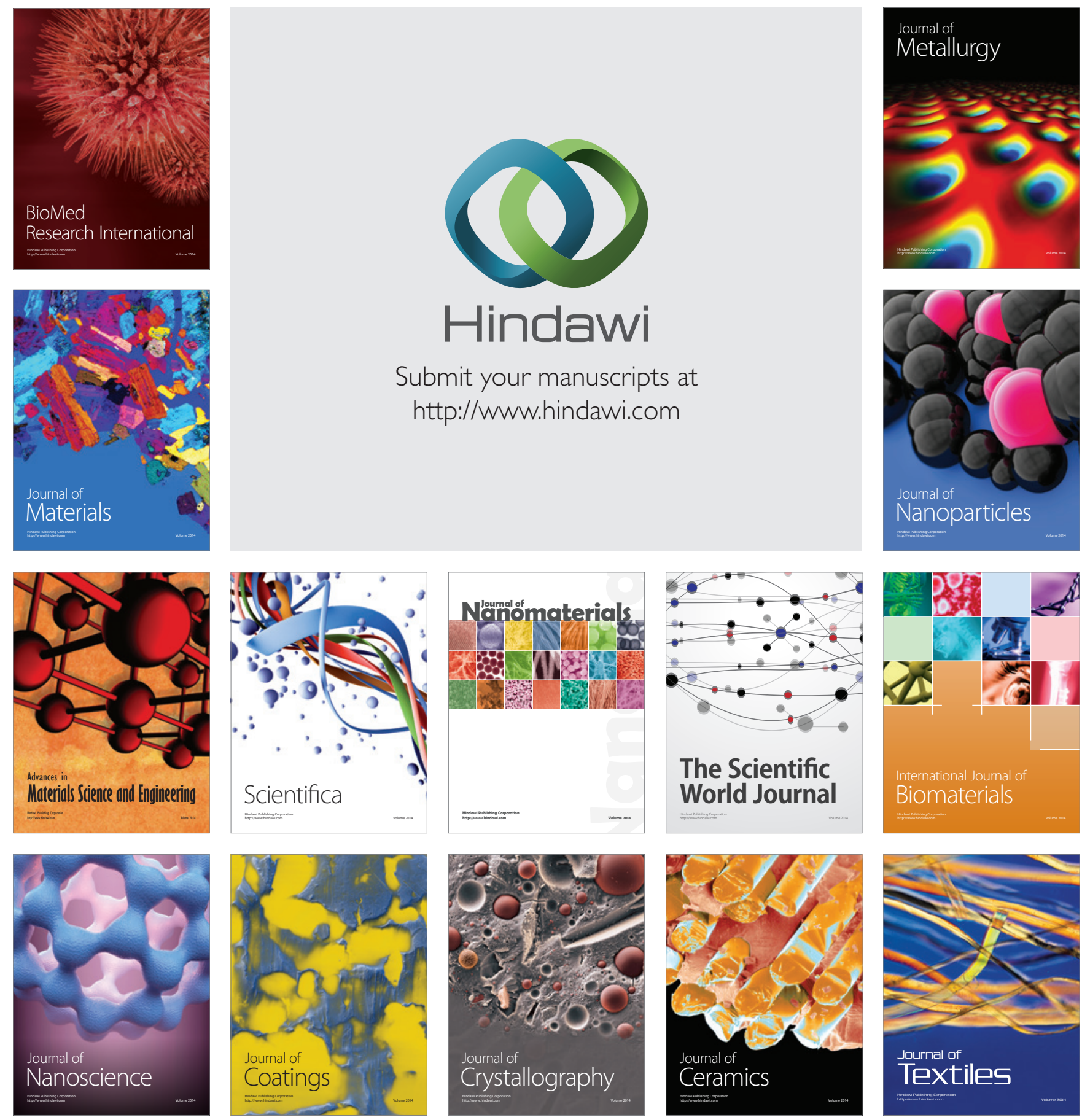